FACULdADE DE CIÊNCIAS ECONÔ MICAS DA UFRGS

MACROECONOMIA DO BRASIL PÓS-1994 LUIZ CARLOS BRESSER-PEREIRA

DESENVOLVIMENTO ECONOMMICO, PREFERÊNCIA PELA LIQUIDEZ E ACESSO BANCÁRIO: UM ESTUDO DE CASO DAS MESORREGIÓES DE MINAS GERAIS

MARCO CROCCO, CLAUDIO BARRA DE CASTRO, ANDERSON CAVALCANTE E VANESSA DA COSTA VAL

FRIEDMAN E O MONETARISMO: A VELHA TEORIA QUANTITATIVA DA MOEDA E A MODERNA ESCOLA MONETARISTA

GENTIL CORAZZAE RODRIGO L. KREMER

BOLLHAS RACIONAIS, CICLO DE PREÇOS DE ATIVOS E RACIONALIDADE LIMITADA: UMA AVALIACAOO CRITICA DOS MODELOS NEOCLÁSSICOS DE BOLHAS ESPECULATIVAS JOSÉ LUIS OREIRO

VULNERABILITY INDICATORS OF THE TWIN CRISES: THE EAST ASIAN EPISODE

TITO BELCHIOR SILVA MOREIRA

IMPACTOS POTENCIAIS DA NEGOCIAÇÃO DA ALCA SOBRE OS INVESTIMENTOS EXTERNOS EM SERVIÇOS PROFISSIONAIS NO BRASIL

MICHEL ALEXANDRE, OTAVIANO CANUTO E GILBERTO TADEU LIMA

TEORIA MARXISTA DO VALOR: UMA INTRODUÇẢO ALFREDO SAAD FILHO

UM ESTUDO EMPIRICO DOS CICLOS POLITICO. ECONOOMICOS NO BRASIL

ATHOS PRATES DA SILVEIRA PREUSSLER E MARCELO SAVINO PORTUGAL

RELENDO CHANDLER, WILLIAMSON E NORTH PARA ENTENDER O PROCESSO DE FORMACĀO DAS ESTRADAS DE FERRO NO BRASIL

JEFFERSON ANDRONIO RAMUNDO STADUTO

WEIMAR FREIRE DA ROCHA IR. E CLAIITON ATAIDES DE FREITAS

MATRIZ DE INSUMO-PRODUTO PARA A ECONOMIA TURISTICA BRASILEIRA: CONSTRUCCÃO E ANÁLISE DAS RELAÇÓES INTERSETORIAIS

FRANCISCO CASIMIRO FILHO E JOAQUIM JOSÉ MARTINS GUILHOTO

SEÇĀO ESPECIAL: AVALIAÇŌES INICIAIS DA POLITTICA ECONÓMICA DO GOVERNO LULA

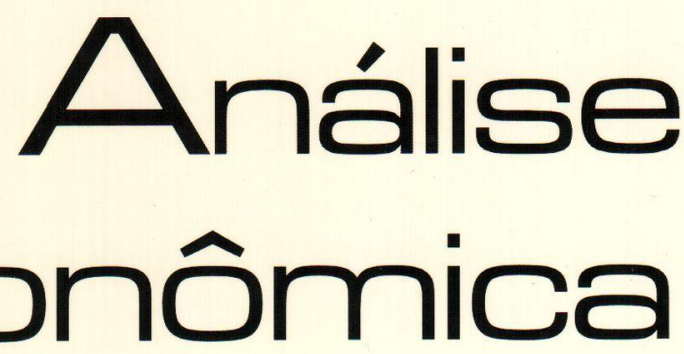


Universidade Federal do Rio Grande do Sul

Reitora: Profa. Wrana Maria Panizzi

Faculdade de Ciencias EConómicas

Diretora: Prof Pedro César Dutra Fonseca

Centro de Estudos e Pesquisas Economicas

Diretor: Prof. Gentil Corazza

Departamento de Ciéncias económicas

Chiefe: Prof. Ricardo Dathein

Curso de Pós. Graduação em Economia

Coordenador: Prof. Eduardo Pontual Ribeiro

Programa de Pós-Graduação em Desenvolvimento Rural

Coordenador: Prof. jalcione Almeida

CONSElHo EDITORIAL:

Carlos G. A. Mielitz Netto (UFRGS), Eduardo A. Maldonado Filho (UFRGS), Eduardo P. Ribeiro (UFRGS), Eleutério F. S. Prado (USP), Eugênio Lagemann (UFRGS), Fernando Cardim de Carvalho (UFRJ), Fernando Ferrari Filho (UFRGS), Fernando de Holanda Barbosa (FGV/RJ), Flávio Vasconcellos Comim (UFRGS), Gentil Corazza (UFRGS), Giácomo Balbinotto Netto (UFRGS), Gustavo Franco (PUC/RJ), Jan A. Kregel (UNCTAD), João Rogério Sanson (UFSC), Joaquim Pinto de Andrade (UnB), Jorge Paulo Araújo (UFRGS), Marcelo S. Portugal (UFRGS), Maria Alice Lahorgue (UFRGS), Paul Davidson (University of Tennessee), Paulo D. Waquil (UFRGS), Pedro C. D. Fonseca (UFRGS), Philip Arestis (Levy Economics Institut of Bard College), Roberto C. de Moraes (UFRGS), Ronald Otto Hillbrecht (UFRGS), Sabino da Silva Porto Jr. (UFRGS), Stefano Florissi (UFRGS) e Werner Baer (University of Illinois at UrbanaChampaign).

COMISSÃO EDITORIAL:

Eduardo Augusto Maldonado Filho, Fernando Ferrari Filho, Gentil Corazza, Marcelo Savino Portugal, Paulo Dabdab Waquil e Roberto Camps Moraes.

EDIroR: Prof. Fernando Ferrari Filho

Editor Adunnio: Prof. Gentil Corazza

SECRETÁrla: Clarissa Roncato Baldim

REVISÁO DE TEXTOS: Vanete Ricacheski

EDITORaÇão Eletrónica: Vanessa Hoffmann de Quadros

Fundador: Prof Antônio Carlos Santos Rosa

Os materiais publicados na revista Análise Econômica são da exclusiva responsabilidade dos autores. É permitida a reprodução total ou parcial dos trabalhos, desde que seja citada a fonte. Aceita-se permuta com revistas congêneres. Aceitam-se, também, livros para divulgação, elaboraçāo de resenhas e recensōes Toda correspondência, material para publicaçāo (vide normas na terceira capa), assinaturas e permutas devem ser dirigidos ao seguinte destinatário:

Análise Econômico

PROF FERNANDO FERRARI FILHO Revisła Análise Econômica - Av. João Pessoa, 52 CEP 90040-000 PORTO ALEGRE - RS, BRASL Telefones: (051) 316-3513 - Fax: (051) 316-3990 E-mail: rae@ufrgs.br

Ano 21, $n^{\circ} 39$, março, 2003 - Porto Alegre

Faculdade de Ciências Econômicas, UFRGS, 2003

Periodicidade semestral, março e setembro.

Tiragem: 500 exemplares

1. Teoria Econômica - Desenvolvimento Regional.

Economia Agrícola - Pesquisa Teórica e Aplicada -

Periódicos. I. Brasil

Faculdade de Ciências Econômicas,

Universidade Federal do Rio Grande do Sul 


\title{
Impactos potenciais da negociação da ALCA sobre os investimentos externos em serviços profissionais no Brasil"
}

\author{
Michel Alexandre** \\ Otaviano Canuto ${ }^{* * *}$ \\ Gilberto Tadeu Lima ${ }^{* * *}$
}

\begin{abstract}
The paper deals with implications of hypothetical results of the negotiations on the Free Trade Area of the Americas on foreign direct investment in some professional services in Brazil. Based upon the presupposition of regulatory convergence/harmonization, whose center of gravity would be located in the most developed economies, it is discussed the extent to which the local environment for the national producers of those services would change with the possibility of greater presence of international competitors.
\end{abstract}

Key words: foreign direct investment, professional services regulation, free trade area.

JEL Classification: F21; F23; L84

\section{Introdução}

O presente texto tem como objeto as implicações de hipotéticos resultados da negociaçāo da Área de Livre Comércio das Américas (ALCA) sobre o Investimento Externo Direto no Brasil em um conjunto selecionado de segmentos no setor de serviços profissionais (serviços legais, serviços contábeis e serviços de engenharia). Partindo-se do pressuposto de homogeneização regulatória, cujo centro de gravidade estaria nas economias desenvolvidas da ALCA, examina-se em que medida o atual panorama para produtores locais, naqueles segmentos, mudaria diante das possibilidades de maior internação de firmas concorrentes estrangeiras.

Com efeito, um dos traços marcantes da evolução recente da economia internacional - e brasileira - tem sido o peso crescente do Investimento Externo Direto (IED), re-configurando nas duas últi-

\footnotetext{
- Artigo elaborado ao longo do ano de 2002.

- Analista econômico do Banco Central do Brasil.

... Professores do Departamento de Economia da FEA-USP.
} 
mas décadas as estruturas de mercado nos diversos espaços nacionais e regionais internacionalizados (Gonçalves et alii, 1998).. Além das implicações macroeconômicas desse processo, o fenômeno importa por suas repercussões em nível de agentes e mercados em particular. O IED expandiu-se de modo explosivo em relação aos PIBs nacionais e ao próprio comércio exterior, desde meados dos anos 80 , acelerando inclusive este último. Nos ramos de serviços muitos dos quais, não obstante a evolução tecnológica, ainda lidam com produtos não-comercializáveis (non-tradables) - o IED emergiu inclusive sem a precedência do comércio exterior.

Cumpre notar, por outro lado, o fato de que, entre os ramos produtivos, é possível encontrar grande variação na intensidade de penetração de investimentos transnacionais, além de sua diferenciaçāo regional. Entre os serviços em particular, há alguns casos em que as "vantagens de localização" próxima ao mercado são imperativas - implicando, portanto caráter não-comercializável em termos internacionais para os respectivos produtos - ao mesmo tempo em que "vantagens específicas a firmas" de países exportadores de capital não se mostram suficientes para viabilizar sua expansão rumo a mercados em particular. Em tais ramos, a provisão e o mercado ainda permanecem de âmbito local, com baixa importância tanto do comércio exterior quanto do IED. Em cada um desses casos, o imperativo da localização do processo produtivo próxima ao mercado local, com segmentação de mercados nacionais, tanto pode ocorrer por razōes tecnológicas e diferenciação de produtos, quanto por dispositivos regulatórios nacionais. Na mesma direção, a ausência de IED também pode decorrer de esses efeitos regulatórios atuarem como barreiras contra "vantagens específicas a firmas" de não-residentes.

No caso brasileiro, pode-se localizar uma diversidade intersetorial no tocante ao grau de penetração de investimentos externos. Mesmo com o forte ingresso de capital de risco nos anos 90 , dirigindo-se inclusive maciçamente para os serviços, ainda é possível encontrar segmentos com baixa participação estrangeira entre estes, por determinantes de natureza técnica ou de caráter regulatório. Entre esses segmentos estão os escolhidos como objeto do presente artigo ${ }^{1}$.

\footnotetext{
${ }^{1}$ Em Canuto, Alexandre 8 Lima (2003), por seu turno, análise semelhante é desenvolvida para os segmentos de seguro-saúde, seguro de crédito à exportação e transportes terrestres.
} 
Um dos temas suscitados, no Brasil, no debate sobre as negociações da ALCA, é o de seus possíveis desdobramentos $\mathrm{m}$ termos da concorrência por mercados locais em diversos setores produtores de serviços. Em meio ao relativo desconhecimento das efetivas condições de oferta e da competitividade dos produtores nacionais de serviços, há o receio de que os resultados das negociações externas venham a expor as empresas atualmente em operação no país à concorrência com competidores externos de maior porte, com melhores práticas gerenciais, melhores condições de acesso a crédito e outras "vantagens específicas a firmas".

A hipótese é que, como resultado da homogeneização entre os aparatos regulatórios dos países envolvidos, a provável supremacia tecnológica e financeira das firmas das economias desenvolvidas envolvidas poderá ser plenamente exercida, em vários casos, uma vez suprimidas as barreiras regulatórias. A ALCA poderia então avançar o processo de internacionalização das estruturas de mercado locais em direção a segmentos ainda relativamente intocados.

Há, ainda, outra dimensão de análise envolvida na questão. Tratase dos efeitos derivados não tanto das condiçōes microeconômicas de cada agente ou do ambiente macroeconômico, mas das diferenças entre os contextos normativos nos quais atualmente operam: Dadas as diferenças em termos de requisitos normativos, entre os países, as empresas habituadas a competir em contextos mais exigentes tenderiam a desenvolver capacidades adicionais em relação a suas potenciais concorrentes, como resposta a seu ambiente menos permissivo. Destarte, supondo-se a homogeneização regulatória de âmbito hemisférico na ALCA, o aprendizado das firmas em contextos originais mais restritivos permitiria a obtenção de relevantes "vantagens específicas a firmas", uma vez retiradas as fricções ao IED contidas em aparatos regulatórios distintos na região ${ }^{2}$.

$\mathrm{O}$ argumento central para essa linha de raciocínio é que - para além das condiçōes de competitividade entre as empresas sediadas em países distintos - haveria um diferencial de competitividade em favor das empresas daquele país onde a regulação (normas para

\footnotetext{
${ }^{2} \mathrm{O}$ que certamente evoca o clássico debate entre $\mathrm{M}$. Porter e W. Oates, no Journal of Economic Perspectives de inverno de 1995 , onde o primeiro convincentemente argumentou acerca da capacitaçāo tecnológica evoluindo como resposta aos problemas suscitados por regulações nacionais mais restritivas na ârea ambiental.
} 
operação) num determinado setor seja relativamente melhor desenhada. Em outras palavras, as empresas que operam num ambiente mais adequado tendem a - ao menos em princípio - tornar-se mais competitivas que as empresas que operam num ambiente regulatório menos propenso a gerar eficiência. $\mathrm{Na}$ hipótese mais provável de ocorrer homogeneização regulatória em torno do aparato mais exigente em termos de eficiência, a necessidade de adaptação imporia desafios competitivos maiores às empresas habituadas a funcionar no contexto menos restritivo e, eventualmente, abriria espaço para maior internacionalização que a presente.

No âmbito da integração hemisférica da ALCA, parece razoável esperar um diferencial de competitividade favorável às empresas estadunidenses e canadenses, em relação às brasileiras, uma vez que o comércio de serviços é mais desenvolvido nessas duas economias que em toda a América Latina. Além dessa diferença como ponto de partida, cabe investigar, também, em que medida as discrepâncias entre os atuais ambientes regulatórios nacionais deverão reforçar ou suavizar "vantagens específicas a firmas" entre empresas de países distintos na região.

Enfim, abordamos no presente artigo os ambientes regulatórios nacionais distintos em que atualmente operam as empresas em certo conjunto selecionado de segmentos de serviços profissionais nos três países. Concentramo-nos em segmentos produtores de serviços onde a penetração de capitais estrangeiros no mercado brasileiro é hoje relativamente reduzida, buscando identificar até que ponto as atuais diferenças normativas poderão implicar vantagens competitivas de empresas dos EUA e Canadá e, portanto, alteração com a ALCA no atual cenário de penetração por firmas estrangeiras no mercado local.

Além desta introdução, o artigo está dividido em mais quatro seçōes. Na segunda, apresenta-se um mapeamento dos investimentos nos segmentos de serviços profissionais selecionados, procurando assim estimar a presença de investidores estrangeiros em operação no Brasil, bem como a origem do capital das principais empresas estrangeiras em operação em cada um deles. Na terceira seção, apresenta-se um breve relato dos principais dispositivos normativos de cada um desses segmentos de serviços, tanto na legislação brasileira quanto nas legislações em vigor nos EUA e Canadá. O objetivo então é oferecer um quadro descritivo dos principais atributos da regulação dos segmentos de serviços abordados. Na quarta seção, a 
partir da análise comparativa, identificam-se as situações em que as condições regulatórias distintas poderão ser marcantes no tocante às vantagens competitivas. As conclusões apontarão possíveis ganhos - entendidos como a capacidade de empresas atualmente presentes em mercados nacionais penetrarem nos mercados de outros países - ou perdas - vistas como menor capacidade das empresas nacionais para competir com empresas sediadas no exterior - derivados das negociações da ALCA, supondo-se homogeneização regulatória e unificação do mercado hemisférico em torno dos arcabouços regulatórios menos permissivos. Por fim, considerações finais ocupam a última seção.

\section{Investimento Direto no Setor de Serviços Profissionais do Brasil}

De acordo com a classificação do GATS (General Agreement on Trade in Services), entende-se por serviços profissionais aqueles prestados por profissionais especializados e sujeitos a licença. Normalmente, os serviços profissionais estão divididos nas seguintes categorias: serviços legais; serviços de contabilidade e auditoria; serviços de taxação; serviços de arquitetura; serviços de engenharia; serviços de planejamento urbano; serviços médicos e odontológicos; serviços veterinários; serviços prestados por parteiros, enfermeiros e fisioterapeutas; e outros serviços.

Os serviços profissionais podem ser divididos em duas categorias mais gerais, quais sejam, os "aprovados" (aqueles que possuem potencial para usufruir acordos de mútuo reconhecimento de qualificaçōes entre os países da $\mathrm{OMC}$ ) e os "não-aprovados". Na primeira categoria, incluem-se os serviços de arquitetura e engenharia, contabilidade e serviços legais. Dentre os serviços "não-aprovados", encontram-se alguns serviços voltados para atividades como marketing, propaganda e consultoria.

Os serviços profissionais podem, ainda, ser classificados de acordo com sua orientação. Dentro desse critério, eles estão divididos em serviços voltados para negócios (propaganda, pesquisa de mercado, contabilidade e auditoria, serviços legais, serviços de arquitetura e engenharia, processamento de dados e geração de softwares) e serviços voltados para consumo (serviços profissionais nas áreas de saúde e educação prestados por médicos, enfermeiros, professores, dentre outros). 
Na classificação do CNAE, os serviços profissionais fazem parte das seguintes categorias: atividades de informática e conexas, pesquisa e desenvolvimento, serviços prestados principalmente às empresas (atividades jurídicas, contabilidade e auditoria, serviços de arquitetura e engenharia, publicidade, dentre outras), educação, saúde e serviços pessoais (lavanderia, tinturaria, tratamento de beleza e do físico corporal, dentre outras).

Os serviços prestados às empresas detinham, em 2000, o segundo maior estoque de IED dentro do setor de serviços, atrás apenas de correio e telecomunicaçōes, mas os fluxos de investimento estrangeiro nesse segmento caíram bastante desde $1998^{3}$. Com relação às demais categorias nas quais os serviços profissionais se incluem, o IED é inexpressivo, com fluxos nulos desde 1996 a $2000^{4}$.

A exceção está nas atividades relacionadas à informática. Boa parte do crescimento do fluxo de IED nesse segmento em 2000 deveu-se aos investimentos no segmento da Internet. Destacaram-se o investimento de US\$ 810 milhões da Telecom Itália nas Organizações Globo e a aquisição, por US $\$ 415$ milhões, da Zip.Net pela PT Multimídia de Portugal.

Outros grupos estrangeiros que aumentaram sua participação nesse setor foram as norte-americanas Microsoft e Diebold e o Grupo Venezoelano Cisneros (CEPAL, 2001). Além disso, cabe destacar, enquanto companhias com participação estrangeira que atuam no setor de informática brasileiro, a Proceda (controle acionário detido pela WorldCom, dos EUA), a Progress Software do Brasil (EUA) e a Veritel Teleinformática (EUA).

Dentro do setor de serviços prestados a empresas, duas categorias detêm a maior parte dos investimentos estrangeiros: os serviços de engenharia e as atividades de consultoria e auditoria. No primeiro grupo, dentre as empresas que possuem algum tipo de participação estrangeira, destacam-se: Logos, Earth Tech, Lemes, Krebs, Bechtel, Engeval, Geocon, Hatch e White Water. No segundo, destacam-se as chamadas " 5 Grandes" empresas de consultoria e auditoria do mundo: a PriceWaterhouse Coopers (Inglaterra), a Arthur

\footnotetext{
${ }^{3}$ Dados recentes indicam uma ligeira recuperação do IED no setor. Após captar $35 \%$ do fluxo total de IED direcionado ao Brasil em 1997, essa cifra caiu para 2,7\% em 2000, mas subiu para $3,3 \%$ e $4,1 \%$ nos dois anos seguintes (CEPAL, 2003).

4 Esses segmentos tiveram fluxos de IED positivos em 2001 (dados do Banco Central do Brasil, em US $\$$ milhōes): pesquisa e desenvolvimento, 0,6; educação, 11,8; saúde, 6,9 ; serviços pessoais, 1,7 .
} 
Ardensen (EUA), a Ernest $\mathcal{E}$ Young (EUA), a KPMG (Alemanha, Holanda e Inglaterra) e a Deloitte and Touche (EUA). Além das " 5 Grandes", outra empresa estrangeira que se destaca no ramo de auditoria e contabilidade é a BDO Directa, de origem belga.

Outros serviços mais específicos de consultoria também contam com a participação de empresas estrangeiras. Na área de consultoria administrativa, destacam-se a A.T. Kearney (EUA), a BovisLend Lease (Reino Unido) e a Brascan do Brasil (Canadá). O ramo de consultoria comercial conta com a presença da suíça Ascher International Consulting. A Amicorp do Brasil (Antilhas Holandesas), a Control Risks (Reino Unido) e a Kroll Associates (EUA) atuam no segmento de consultoria econômico-financeira, e a Goldfarb Consultants (Canadá), de consultoria em marketing. O setor de consultoria de negócios conta com a participação da BIB Participações (Holanda). No setor de consultoria em recursos humanos, estão empresas como a Boyden do Brasil (EUA), a Korn/Ferry International (EUA), a Lens e Minarelli (parceria com a Career Partners International, dos EUA), a Michael Page International (EUA) e a Roland Berger Consultoria (Alemanha). Por fim, a Control Union (Holanda) a Cotecna (Suíça) realizam serviços de inspeção.

Ainda com relação a investimentos estrangeiros no setor de serviços profissionais brasileiro, cumpre destacar a joint-venture criada entre a IFS (Industrial $\mathcal{B}$ Financial Systems), empresa de informática norte-americana, e a Total Service Serviços Contábeis, empresa originária da terceirização dos serviços de contabilidade da Trevisan. Essa parceria tem o objetivo de oferecer serviços de outsourcing (terceirização) às empresas.

\section{Regulação de Serviços Selecionados no Brasil, nos Esta- dos Unidos e no Canadá}

Nesta segunda seção, pretende-se fazer uma breve descrição do arcabouço regulatório dos três segmentos de serviços profissionais selecionados em vigor no Brasil, nos Estados Unidos e no Canadá. As subseções seguintes tratarão, desse modo, do aspecto regulatório referente a cada um desses segmentos, a saber, serviços de engenharia, serviços legais e serviços contábeis. O objetivo é recolher informações pontuais dispersas sobre tais arcabouços regulatórios, de modo a fundamentar a avaliação realizada na seção seguinte. 
Este estudo será feito levando-se em conta essencialmente seis aspectos: regulação relativa às principais atividades desses profissionais, requerimentos de qualificação profissional, regulação relativa a associações ou organizações profissionais, regulação relativa a conduta dos agentes (formas de estabelecimento, tarifas e propaganda enganosa), regulação que afeta transações internacionais realizadas por pessoas naturais de outros países e regulação que afeta transaçōes internacionais realizadas por firmas estrangeiras. No caso brasileiro, as informaçōes foram obtidas consultando-se a legislação pertinente a cada tema. Nos casos norte-americano e canadense, a principal referência utilizada foi OECD (2000).

\subsection{Brasil}

Serviços de engenharia

Com relação às principais atividades realizadas por prestadores de serviços de engenharia no país, a Lei $n^{2} 5.194$, de 1966, enumera as seguintes:

1. desempenho de cargos, funções e comissões em entidades diversas;

2. planejamento e projetos diversos;

3. estudos, projetos, análises, avaliações, vistorias, perícias, pareceres e divulgação técnica;

4. ensino, pesquisa, experimentação e ensaio;

5. fiscalização de obras e serviços técnicos;

6. direção de obras e serviços técnicos;

7. execução de obras e serviços técnicos;

8. produção técnica especializada.

Ainda segundo aquela Lei, as atribuições de 1 a 6 podem ser realizadas apenas por pessoas físicas. Entidades jurídicas só poderão realizá-las com a participaçáo efetiva e autoria declarada de um profissional legalmente habilitado e registrado pelo Conselho Regional de Engenharia e Arquitetura (CREA). Por fim, as atribuições 7 e 8 poderão ser realizadas indistintamente por pessoas físicas ou jurídicas. As demais atividades passiveis de ser realizadas por engenheiros, não citadas nessa Lei, podem ser desenvolvidas por quaisquer engenheiros. A Lei $n^{2} 7.410$, de 1985, por sua vez, estabelece que a 
profissão de Engenheiro de Segurança do Trabalho só poderá ser exercida por engenheiro portador do certificado de conclusão de curso de especialização em Engenharia de Segurança do Trabalho, em nível de pós-graduação.

Para obter a qualificação profissional, o engenheiro deve ser graduado em algum curso de Engenharia, o que implica ao menos quatro anos de estudos universitários (Lei n 5.194). No entanto, não se exige que o mesmo possua experiência profissional prévia. Para exercer legalmente as atividades a eles reservadas, os engenheiros devem ser filiados ao CREA correspondente a sua região (Lei n 5.194).

Não é feita nenhuma restrição mais explícita às taxas cobradas pelos profissionais de engenharia, mas estabelece-se que a disputa por projetos não pode desencadear uma concorrência de preço, devendo, quando for o caso, haver a realização de um concurso (Lei $n^{\circ}$ 5.194). Nenhuma restrição é imposta à realização de propaganda, a menos que o profissional de engenharia não esteja devidamente registrado (Decreto $\mathrm{n}^{\circ} 23.569$, de 1933).

A Lei $n^{\circ} 4.950-A$, de 1966 , dispõe sobre a remuneração dos profissionais de engenharia. Essa Lei estabelece um salário base mínimo de seis salários mínimos, para profissionais que se formaram em cursos de pelo menos quatro anos de duração, e de cinco salários mínimos, para os demais profissionais. Caso o profissional trabalhe mais de seis horas diárias, as horas excedentes serão pagas com $25 \%$ de acréscimo.

Profissionais estrangeiros podem ser registrados temporariamente, a critério dos CREAs, desde que haja escassez de profissionais brasileiros numa determinada especialidade e interesse nacional na contratação de estrangeiros. Empresas que fizerem contratação de profissionais estrangeiros deverão manter junto a eles um profissional brasileiro do ramo profissional respectivo (Lei $n^{2}$ 5.194). Exigese também que engenheiros estrangeiros residam previamente no país.

Não se aplica nenhuma restrição específica à entrada de empresas estrangeiras prestadoras de serviços de engenharia . No entanto, a elas se aplicam as mesmas restrições impostas às pessoas jurídicas prestadoras de serviços de engenharia, inclusive no que se refere à contratação de profissionais estrangeiros, já citadas anteriormente.

Serviços legais

Com relação às atividades realizadas por prestadores de serviços legais, várias delas são reservadas legalmente para advogados 
inscritos na Ordem dos Advogados do Brasil (OAB): diretoria jurídica de uma empresa, assessoramento jurídico nas transações imobiliárias e na redação de contratos e estatutos de sociedades civis e comerciais, elaboração de defesas, escritas ou orais, perante quaisquer tribunais e repartiçōes, e elaboração de memoriais do âmbito da Lei do Condomínio, no que concerne, estritamente, à sua fundamentação jurídica. A prestação de qualquer tipo de assistência jurídica, sistemática a terceiros, nela incluída a cobrança judicial ou extrajudicial, é atividade privativa de sociedade constituída apenas de inscritos, registrada na Ordem dos Advogados, de acordo com a Lei $n^{2} 4.215$, de 1963 (Provimentos $n^{9} 66$, de 1988, e $n^{\circ} 69$, de 1989).

Para obter a qualificação profissional, o advogado deve sèr graduado em algum curso de Direito, o que implica ao menos quatro anos de estudos universitários. No entanto, não se exige que o mesmo possua experiência profissional prévia. Para exercer legalmente as atividades a eles reservadas, os advogados devem ser filiados à OAB (Provimentos $n^{\circ} 66$, de 1988, e $n^{\circ} 69$, de 1989). Para tanto, o mesmo deve passar por um exame de qualificação.

Com relação às formas de estabelecimento, estipula-se que as firmas de advocacia não podem assumir a forma de sociedade por quotas de responsabilidade limitada, nem de sociedades em comandita ou por ações. Estabelece-se também que associações entre sociedades de advogados não podem conduzir a que estas se tornem sócias (Provimento $\mathrm{n}^{2}$ 92, de 2000).

O Provimento $n^{\circ} 94$, de 2000 , restringe a realização de propaganda por prestadores de serviços legais. É permitida a realização de propaganda por parte dos prestadores de serviços legais, desde que a mesma expresse "dados verdadeiros e objetivos".

Alguns comportamentos e meios de publicidade não são permitidos, de modo a evitar a realização de propaganda enganosa. É proibido, na publicidade de um advogado:

a. menção a clientes ou a assuntos profissionais e a demandas sob seu patrocínio;

b. referência, direta ou indireta, a qualquer cargo, função pública ou relação de emprego e patrocínio que tenha exercido;

c. emprego de orações ou expressões persuasivas, de auto-engrandecimento ou de comparação;

d. divulgação de valores dos serviços, sua gratuidade ou forma de pagamento;

e. oferta de serviços em relação a casos concretos e qualquer 
convocação para postulação de interesses nas vias judiciais ou administrativas;

f. veiculação do exercício da advocacia em conjunto com outra atividade;

g. informaçōes sobre as dimensões, qualidades ou estrutura do escritório;

h. informações errôneas ou enganosas;

i promessa de resultados ou indução do resultado com dispensa de pagamento de honorários;

j. menção a título acadêmico não reconhecido;

k. emprego de fotografias e ilustraçōes, marcas ou símbolos incompativeis com a sobriedade da advocacia; cantil.

1. utilização de meios promocionais típicos de atividade mer-

Os meios de publicidade que não podem ser utilizados pelos advogados são: rádio, televisão, publicidade em vias públicas, panfletos, cartas circulares e oferta de serviços mediante intermediários.

Advogados estrangeiros que queiram atuar no país poderão trabalhar apenas como consultores em direito estrangeiro, correspondente ao seu país de origem, sendo-lhes vedados o exercício do procuratório judicial e a consultoria e assessoria em direito brasileiro. Além disso, para atuar no país, os mesmos precisam de autorização da OAB e portar visto de residência no país (Provimento $n^{\circ} 91$, de 2000).

Da mesma forma, as firmas estrangeiras de advocacia poderão atuar somente na área de consultoria em direito estrangeiro, correspondente a seu país de origem. Os advogados estrangeiros que façam parte da mesma devem todos estar autorizados pela $\mathrm{OAB}$ e exige-se que a firma tenha sede no país (Provimento $\mathrm{n}^{\circ}$ 91, de 2000).

Serviços contábeis

Com os escândalos financeiros nos Estados Unidos e a aprovação do Sarbanes-Oxley Act ${ }^{5}$ em julho de 2002, a prestação de serviços contábeis a instituições financeiras tornou-se mais rigidamente regulamentada no Brasil. Com a Resolução 3.081 do Banco Central, de maio de 2003, todas as instituições financeiras com patrimônio de referência superior a $R \$ 200$ milhões deverão possuir um comitê de auditoria que poderá, dentre outras coisas, recomendar a

\footnotetext{
${ }^{5} \mathrm{Na}$ seção que analisa a regulação de serviços contábeis nos Estados Unidos, o Sarbanes-Oxley Act é tratado com mais detalhes.
} 
contratação ou substituição da firma prestadora de serviços de auditoria. Várias situações que possam afetar a independência do auditor (participação acionária na empresa auditada, operações ativas ou passivas junto à firma auditada, pagamento de honorários ou reembolso de despesas superiores a $25 \%$ do rendimento anual do auditor, etc.) passam a ser proibidas. Por fim, outro impacto importante da resolução sobre as firmas prestadoras de serviços contábeis a instituiçōes financeiras é a imposição de que a empresa deve substituir o auditor após a emissão de pareceres relativos a cinco exercícios sociais e que o mesmo só poderá ser recontratado após três anos.

Com relação às principais atividades desenvolvidas por prestadores de serviços contábeis, algumas delas estão reservadas legalmente para contadores diplomados: perícias judiciais ou extrajudiciais, revisão de balanços e de contas em geral, verificação de haveres, revisão permanente ou periódica de escritas, regulações judiciais ou extrajudiciais de avarias grossas ou comuns e assistências aos Conselhos Fiscais das sociedades anônimas. Outras atividades (organização e execução de serviços de contabilidade em geral e escrituração dos livros de contabilidade obrigatórios) são compartilhadas com profissionais de outras áreas (Decreto-Lei $\mathrm{n}^{\mathrm{Q}} 9.295$, de 1946).

Para obter a qualificação profissional, o contador deve ser graduado em algum curso de Contabilidade, o que implica, no país, ao menos quatro anos de estudos universitários (Decreto-Lei $\mathrm{n}^{\circ}$ 9.295, de 1946). Não se exige que o mesmo possua experiência profissional prévia. Para exercer legalmente as atividades a eles reservadas, os contadores devem ser filiados ao Conselho Regional de Contabilidade (CRC) correspondente a sua região (Decreto-Lei $n^{9} 9.295$, de 1946).

Nenhuma restrição é feita à realização de propaganda por parte dos prestadores de serviços contábeis, a não ser que o mesmo não esteja devidamente registrado (Decreto-L.ei n² 9.295, de 1946). Além disso, nenhuma restrição é feita com relação a profissionais ou firmas estrangeiras prestadores de serviços contábeis que atuem no país, a não ser a exigência de residência prévia.

\subsection{Estados Unidos}

Serviços de engenharia

Normalmente, as atividades prestadas principalmente por engenheiros são reguladas e reservadas apenas para um tipo específi- 
co de profissional dentro da atividade. A única notória exceção está nos estudos de viabilidade, que é uma atividade regulada e exercida por profissionais de diferentes áreas que não necessariamente a engenharia.

Para obter a qualificação nacional, um engenheiro deve ter ao menos quatro anos de estudos universitários e quatro anos de experiência profissional. É necessário, também, a realização de um exame de qualificação profissional. Não existe a obrigatoriedade de que o engenheiro torne-se membro de uma organização ou associação profissional.

Apenas alguns tipos de incorporações entre firmas de engenharia são permitidos no país. Por outro lado, nenhum tipo de restrição é imposta às taxas cobradas pelos serviços oferecidos por profissionais de engenharia e à propagada realizada pelos mesmos. Em 1978, a National Society of Professional Engineers teve sua tentativa de estabelecer preços mínimos aos serviços prestados por seus membros, alegando que baixos preços induzem os profissionais a prestarem serviços de pior qualidade, frustrada pela Suprema Corte dos Estados Unidos.

Para engenheiros estrangeiros que queiram atuar no país, nenhum requerimento explícito com relação à nacionalidade ou à residência prévia é imposto. No entanto, os mesmos devem obter uma licença para realizar suas atividades em território americano.

As restrições aparecem no tocante a empresas. Com relação a firmas estrangeiras prestadoras de serviços de engenharia, há restrições relativas ao investimento das mesmas no país e, caso venham a se instalar, deverão empregar um número mínimo de norte-americanos.

Serviços legais

A regulação dos serviços legais no país é realizada em nível estadual. As entidades responsáveis por isso são as Bar Associations de cada estado norte-americano.

As principais atividades que competem a prestadores de serviços legais normalmente são reguladas e realizadas por diferentes profissionais da área de advocacia. Representação perante cortes, conselhos referentes a assuntos regulamentados por lei e lei de patentes são atividades que se encaixam nessa situação. No entanto, representação perante agências administrativas é uma atividade regulada e realizada por profissionais diversos que não exatamente advogados. 
Para obter qualificação nacional, os advogados dos Estados Unidos devem submeter-se a no mínimo sete anos de estudos e passar por um exame de qualificação. No entanto, os mesmos não precisam possuir experiência prática para isso.

Nos Estados Unidos, os profissionais ligados a serviços legais (advogados, advogados de patentes, consultores) não são obrigados a ser membros de alguma organização ou associação profissional, no caso, a Bar Association correspondente a seu estado.

Apenas alguns tipos de incorporaçăo entre firmas de advocacia são permitidos . No entanto, nenhuma restrição é imposta às taxas cobradas pelos prestadores de serviços legais, nem à realização de propaganda pelos mesmos. Normalmente, a Bar Association de um determinado estado consegue alterar a aplicação do Sherman Act, a lei federal norte-americana que inibe práticas anticompetitivas. Foi o caso do State Bar of Arizona, que em 1977 garantiu a seus associados o direito de realizarem propaganda conforme vinham fazendo. No entanto, há situações nas quais a Suprema Corte norte-americana não identifica soberania na ação do estado e, portanto, não torna sua State Bar imune ao Sherman Act. Isso aconteceu com o Virginia State Bar em 1975, quando tentou estabelecer preços mínimos aos serviços prestados por seus associados.

Aos profissionais estrangeiros ligados a serviços legais que queiram atuar no país, há restrições em termos de exigência de residência prévia e o mesmo deve passar por uma requalificação.

As firmas estrangeiras de serviços legais que queiram atuar em território americano sofrem restriçōes no que diz respeito à exigência de presença local. Com relaçāo aos demais tópicos (investimentos, número mínimo de profissionais locais, contratação de profissionais locais e parcerias, associações e joint-ventures com firmas americanas), não há restrições na legislação de cunho geral.

\section{Serviços contábeis}

Em julho de 2002, foi aprovado o Sarbanes-Oxley Act (SOA), um importante marco na regulação dos serviços contábeis nos Estados Unidos. A criação dessa lei foi motivada principalmente pela sequêencia de escândalos financeiros envolvendo grandes empresas norteamericanas como a Enron e a Worldcom. Os objetivos centrais dessa nova lei são garantir a independência da auditoria das contas da empresa e aumentar a transparência da situação financeira das empresas e das técnicas de auditoria utilizadas. 
Uma das principais inovações trazidas pelo SOA é a criação do Public Company Accounting Oversight Board (PCAOB), um organismo de supervisão das empresas de auditoria contabilística e financeira. Essas empresas deverão se registrar no $\mathrm{PCAOB}$ e estarão sujeitas aos seus poderes de regulação e supervisão. Outro importante impacto do SOA sobre as firmas de serviços contábeis é a obrigatoriedade da existência, em todas as empresas, de um comitê de auditoria, que irá supervisionar a firma de contabilidade contratada pela empresa. As demais mudanças impostas pelo SOA que influenciam a prestação de serviços contábeis incluem a proibição da sobreposição de serviços de consultoria e assessoria aos de auditoria e a obrigatoriedade da rotação periódica dos auditores de cada empresa.

As várias modalidades de auditoria (estatutária, do setor público e de fusões) são reguladas por e reservadas apenas a contadores. $A$ análise de insolvência é uma atividade regulada e realizada por profissionais diversos que não necessariamente contadores.

Para obter qualificação nacional, os contadores devern atender aos seguintes requisitos: no mínimo quatro anos de estudos universitários, ao menos de dois a três anos de experiência profissional e aprovação em exame profissional de qualificação.

Nos Estados Unidos, contadores, auditores e consultores de impostos não são obrigados a filiar-se a organização ou associação profissional. A maioria dos membros das organizações estaduais também se filia à organização nacional. As organizações estaduais não atuam no estabelecimento de padrões regulatórios, sendo isso realizado em nível nacional.

Apenas alguns tipos de incorporações entre firmas de serviços contábeis são permitidos no país. Com relação aos demais tópicos (associaçōes intraprofissionais, taxas e propaganda), nenhuma restrição é imposta. Por vezes, é necessário a ação federal para garantir que os estados, responsáveis pela regulação do setor, inibam a livre concorrência. Como exemplo, pode ser citado o caso do Texas State Board of Public Accountancy. Em 1978, o Texas Board tentou estabelecer uma lei que baniria ações competitivas por parte dos contadores públicos daquele estado, o que foi proibido pela District Court e pela Court of Appeals.

Contudo, aos profissionais de serviços contábeis estrangeiros atuantes no país são aplicadas restrições quanto à exigência de residência prévia e quanto à obtenção de licença para atuar no país. Por seu turno, as firmas estrangeiras de serviço contábeis atuantes 
no país sofrem restrições no que diz respeito a investimentos, número mínimo de profissionais locais e, em menor grau, exigência de presença local.

\subsection{Canadá}

Serviços de engenharia

As atividades realizadas principalmente por engenheiros no país quase sempre são reguladas e restritas apenas a algum tipo específico de profissional dentro do ramo da engenharia. A exemplo do que ocorre também nos Estados Unidos, a realização de estudos de viabilidade pode ser regulada e realizada por profissionais de diferentes áreas que não necessariamente a engenharia.

No Canadá, a qualificação nacional só é conferida a um engenheiro que tenha passado por no mínimo quatro anos de estudos universitários e que tenha ao menos quatro anos de experiência profissional. O mesmo deve passar também por um exame de qualificação profissional. O engenheiro, no país, deve fazer parte obrigatoriamente de alguma organização ou associação profissional. Além disso, nenhum tipo de restrição é imposto à realização de incorporações de firmas de engenharia, às taxas cobradas pelos serviços realizados por engenheiros e à realização de propaganda pelos mesmos.

Para engenheiros estrangeiros que queiram atuar no país, nenhuma restrição é imposta à nacionalidade do mesmo. Há, no entanto, algum grau de regulação que incide sobre as exigências de residência prévia no país, e o mesmo deve obter uma licença para atuar em território canadense. Uma regulação mais restrita se aplica aos investimentos de firmas estrangeiras de engenharia e há um número mínimo de profissionais canadenses que as mesmas devem contratar para atuar no território local. Restriçōes não são estabelecidas para a realização de parcerias, associações e jointventures com empresas de engenharia canadenses.

Serviços legais

A maioria das principais atividades relacionadas a serviços legais (representação perante corte, conselhos em assuntos regidos por lei, transferência de bens e leis de patente) é regulada e realizada por diferentes profissionais dentro da área de advocacia. Já a representação perante agências administrativas é regulada e realizada por profissionais não necessariamente da área de advocacia. 
Para obter qualificação nacional, o advogado deve atender aos seguintes requisitos: no mínimo de quatro a sete anos de estudos universitários, de meio a um ano de experiência profissional e aprovação num exame profissional. A maioria dos profissionais ligados a serviços legais (advogados, juízes, consultores legais) deve fazer parte, obrigatoriamente, de alguma associação ou organização profissional. Ademais, é proibida a incorporação entre firmas prestadoras de serviços legais.

Profissionais estrangeiros prestadores de serviços legais sofrem restriçōes no que diz respeito a exigência de residência prévia e de requalificação. As firmas estrangeiras prestadoras de serviços legais no país, por sua vez, sofrem restrições com relação a vários tópicos: investimentos, número mínimo de profissionais locais, associações, parcerias e joint-ventures com firmas canadenses e, em menor grau, exigência de presença local.

\section{Serviços contábeis}

Quase todas as atividades relacionais a serviços contábeis (auditoria prevista em estatutos, auditoria do setor público, auditoria de fusões e análise de insolvência) são reguladas e realizadas por profissionais de diferentes áreas, que não necessariamente contabilidade. A atividade de contabilidade, como nos Estados Unidos, não é regulada. Para obter qualificação nacional, prestadores de serviços profissionais devem atender aos seguintes requisitos: no mínimo quatro anos de estudos universitários, de dois a dois e meio anos de experiência profissional e aprovação num exame profissional.

Os contadores devem fazer parte, obrigatoriamente, de alguma organização ou associação profissional. Como nos Estados Unidos, a maior parte dos membros das organizações provinciais participa também da organização federal, e o estabelecimento de padrões regulatórios é realizado apenas em nível federal. No caso de certas atividades prestadas por profissionais de serviços contábeis, a incorporação é proibida. Aos profissionais dessa área também são impostas restrições referentes a práticas multidisciplinares.

Profissionais estrangeiros de serviços contábeis sofrem restrição com relação a exigência de residência prévia e precisam de licença para atuar no país. Da mesma forma, firmas estrangeiras de serviços contábeis sofrem restrições no que diz respeito a investimentos e, em menor grau, a exigência de presença local e número mínimo de profissionais locais. 


\section{Regulação e Vantagens Específicas a Firmas em Serviços Profissionais Selecionados}

Em que medida as diferenças nos arcabouços regulatórios descritos na seção anterior, uma vez suavizadas em alguns de seus aspectos centrais no contexto das negociaçōes da ALCA, poderão afetar a competitividade das firmas brasileiras, canadenses e norte-americanas nos segmentos de serviços profissionais aqui abordados? Pode-se concluir algo acerca de eventuais conseqüências em nível de investimentos internacionais, com eventual alteração no quadro descrito nos seçōes iniciais? Crescerão, diminuirão ou permanecerão definidas por outros fatores as "vantagens específicas a firmas" brasileiras, canadenses e norte-americanas como resultado de tal homogeneização, tomando-se como suposto que os novos termos regulatórios se aproximariam daqueles vigentes nas economias desenvolvidas?

No que segue, apresentamos as conclusões acerca de cada um dos segmentos selecionados para o presente artigo. O procedimento consiste em destacar as implicações, em termos de "vantagens específicas a firmas" e de IED, para cada uma das significativas alterações possíveis nos arcabouços de regulação nacional. Como referência, tomaremos a descrição na seção anterior, bem como alguns resultados recém-estabelecidos na literatura internacional sobre as relações entre regulação e competitividade em cada um dos segmentos analisados.

O tipo de regulação que assegura a qualidade dos serviços profissionais prestados vai depender, em primeira instância, do tipo de cliente que demanda o serviço (OECD, 2000).

Os serviços profissionais podem ser classificados como: (i) serviços voltados principalmente para grandes corporaçōes empresariais e (ii) serviços voltados principalmente para clientes individuais. No primeiro tipo, incluem-se atividades como propaganda, pesquisa de mercado, contabilidade e auditoria, serviços legais, serviços de arquitetura e engenharia, processamento de dados e geração de softwares. A segunda categoria engloba serviços profissionais nas áreas de saúde e educação, prestados por médicos, enfermeiros, professores, entre outros.

As grandes corporaçōes possuem conhecimento que lhes permite julgar a qualidade dos serviços que lhes são oferecidos. Possu- 
em, também, grande poder de negociação junto aos provedores de serviços profissionais. Essas duas qualidades conferem às grandes corporaçōes, portanto, grande capacidade de autoproteção, permitindo-lhes demandar serviços de alta qualidade dos provedores de serviços profissionais (OECD, 2000).

Clientes individuais, por sua vez, não são tão capazes de julgar adequadamente a qualidade dos serviços que lhes são oferecidos e não possuem grande poder de negociação junto a provedores de serviços profissionais. É necessário, portanto, que haja certo grau de competição entre os provedores de serviços profissionais para clientes individuais, de modo a assegurar a qualidade dos serviços por eles prestados (OECD, 2000) .

Portanto, o arcabouço regulatório voltado para serviços profissionais prestados a grandes corporações necessita não muito mais que garantir o livre comércio dos serviços, já que as grandes corporações têm poder para exigir a qualidade dos serviços prestados. Já no caso de clientes individuais, apesar de se beneficiarem da competição de preços e de qualidade entre os provedores de serviços profissionais, são necessárias algumas proteçōes regulatórias para garantir a qualidade dos serviços (OECD, 2000).

Teoricamente, há certa incompatibilidade entre a manutenção da qualidade dos serviços prestados e a competição entre os prestadores de serviços profissionais. Para garantir a qualidade dos serviços, podem ser adotadas algumas medidas regulatórias - restrições à entrada no mercado, inclusive de provedores estrangeiros, estabelecimento de preços mínimos, restrições à realização de propaganda e a associações comerciais - que acabam por reduzir o grau de competição, resultando em maiores preços e menor oferta de serviços (OECD, 2000) ${ }^{7}$.

No entanto, não é necessário - e muito menos razoável - eliminar toda a competição do setor para assegurar a qualidade dos serviços profissionais. Até porque vários estudos empíricos descartam a existência de uma relação entre menor competição e maior quali-

\footnotetext{
${ }^{6}$ Corroborando essa idéia, Stephen (2001) ressalta que, na literatura econômica, a regulação de serviços legais normalmente justifica-se por problemas de risco moral e seleção adversa, advindos da assimetria de informaçōes entre prestadores e consumidores de serviços legais.

7 As evidências empíricas sobre tal ponto, no entanto, são controversas. Feldman e Begun (1985), por exemplo, concluíram que a maior regulação das atividades prestadas por oftalmologistas nos Estados Unidos reduz a competição, amplia os preços e aumenta a qualidade dos serviços prestados. Porém, no mercado de serviços legais, por exemplo, estudos microeconométricos não sustentam a hipótese de que restrições à entrada aumentam a renda dos prestadores desses serviços (Stephen 2001).
} 
dade. Alguns, inclusive, sustentam que a diminuiçāo da competitividade no setor de serviços profissionais aumenta os preços e reduz a qualidade dos serviços prestados.

OFT (2001) coloca que restrições à oferta de serviços profissionais tende a elevar custos e preços e a inibir a inovação no setor. Um estudo realizado pela Industry Commission da Austrália conclui que a permissão de práticas competitivas não reduz a qualidade dos serviços adquiridos pelos clientes. OECD (2000), revisando onze estudos comparativos, mostra que, em seis, a qualidade mostrou-se neutra diante do grau de competição, em dois a qualidade aumentou com as restriçōes à competição e, nos outros três, caiu após a redução da competição. Sua conclusão geral é que a maior competição não necessariamente reduz a qualidade dos serviços prestados.

Dentro da hipótese de que uma maior competição no setor de serviços profissionais é benéfica (ou, ao menos, não é nociva) à qualidade dos serviços prestados, restrições à realização de propaganda poderiam prejudicar o setor, uma vez que isso desestimula a competição. Schroeter et alii (1987), estudando práticas de propaganda em dezessete áreas metropolitanas dos Estados Unidos no setor de serviços legais, concluíram que a realização de propaganda por parte de prestadores de serviços legais aumenta a competiçáo entre os mesmos. OECD (2000) chegou a conclusões semelhantes, constatando que o anúncio de menores preços atrai maior volume de clientes e reduz o custo fixo médio. Assim, a firma pode oferecer menores preços sem reduzir a qualidade dos serviços prestados. Bortolotti (2000) também observa que a abolição de restrições à realização de propaganda traz efeitos benéficos.

Mesmo restrições baseadas em critérios de qualidade, para assegurar que apenas provedores mais qualificados atuem no mercado, não devem ser muito rigorosas. Vários estudos, levantados em OECD (2000), concluíram que, sob altos padrões de qualificação exigidos, cai a qualidade média dos serviços prestados. Isso ocorre porque os consumidores, ao se depararem apenas com serviços de alto preço/qualidade, farão eles próprios os serviços, reduzindo a qualidade média dos serviços que são prestados. Críticos da reserva de mercado apenas a profissionais altamente qualificados apontam que uma certificação seria mais benéfica que tal procedimento, pois os preços dos serviços seriam menores (já que a oferta năo seria 
restrita), e a qualidade dos mesmos seria razoavelmente mantida (Kleiner, 2000) ${ }^{8}$.

A questão-chave, portanto, é relaxar as restrições à competição que não são necessárias para manter a qualidade dos serviços profissionais (OECD, 2000). A presença de restrições justifica-se em quatro situaçōes: se servirem ao interesse público, se servirem ao progresso econômico, se os benefícios forem divididos com os consumidores e se não eliminarem a competição (OFT, 2001). Os entraves à competição considerados inúteis para a qualidade dos serviços enquadram-se em quatro tipos (OECD, 2000):

1. Restrições à entrada e acesso. Os controles à entrada podem se dar em dois níveis: a determinação de quem pode obter a licença para atuar e a determinação das escolas cujos diplomados são aceitos como profissionais habilitados a atuar na profissão. É pouco provável que seja necessário utilizar ambos os níveis para assegurar a qualidade dos serviços. Combinadas com restriçōes aos tipos de serviços que podem ser ofertados, barreiras à entrada também inibem a competição na forma de novos produtos e/ou provedores.

2. Restrições à competição por preços. O estabelecimento de taxas mínimas a ser cobradas por serviços profissionais prestados impede que os provedores realizem uma competição de preços entre $\mathrm{si}^{9}$. Em alguns lugares, como nos Estados Unidos, por exemplo, mesmo o estabelecimento de taxas máximas é considerado anticompetitivo, pois o uso de escalas máximas poderia tornar-se justificativa para manter os preços acima dos preços competitivos.

3. Restrições à realização de propaganda não-enganosa. A propaganda é um importante meio para informar os consumidores a res. peito de novos produtos, serviços e provedores. Portanto, ela encoraja a inovação e a nova entrada. Restrições à realização de propaganda não-enganosa desestimulam a inovação e a competitividade no setor.

4. Restriçōes a formas alternativas de prática dos serviços. Em serviços profissionais, relações de corporação, franchising e até mesmo estabelecimento de filiais são freqüentemente proibidos. Relações de parceria, corporação e emprego com não-praticantes da profissão também sofrem sérias restrições. Em várias situações, essas restrições foram relaxadas, pois impedem a formação de estruturas de custo

\footnotetext{
${ }^{8} \mathrm{Na}$ entrada regulada por certificação, qualquer pessoa pode atuar no mercado, mas há um órgão regulador que administra um exame de qualificação e certifica os aprovados no mesmo, divulgando seu nível de habilidade ou conhecimento.

9 Argumentação semelhante é desenvolvida por Bortolotti (2000).
} 
mais eficientes. Restrições a parcerias entre profissionais locais e estrangeiros são importantes obstáculos à competição internacional.

Portanto, o arcabouço regulatório que incentiva maior eficiência dentro do setor de serviços profissionais é aquele que assegura a qualidade dos serviços prestados a pequenos clientes, mas sem estabelecer restrições que prejudiquem a competição do setor e que levem a uma menor qualidade dos serviços prestados. Em suma, as restrições devem se circunscrever ao mínimo necessário para atingir os objetivos de proteção ao consumidor (OFT, 2001).

O Quadro 1 resume os principais traços da regulação dos segmentos de serviços profissionais em questão nos Estados Unidos, Brasil e Canadá. Em quase todos os casos, há um certo número de atividades reservadas exclusivamente a profissionais qualificados da área. Isso representa uma desvantagem em comum para firmas de serviços profissionais de todos os países, já que as mesmas não competem com profissionais de outras áreas. A exceção fica para as firmas de serviços contábeis do Canadá, onde os principais tipos de auditoria (estatutória, do setor público, de fusões e análise de insolvência) são realizados também por profissionais de outras áreas $\mathrm{e}$ não necessariamente da contabilidade.

A qualificação mínima exigida para que provedores de serviços profissionais possam atuar é muito maior nos casos canadense $\mathrm{e}$ norte-americano que no brasileiro. Normalmente, nos Estados Unidos e no Canadá, além de um número mínimo de estudos universitários, exige-se que o profissional possua também alguns anos de experiência profissional (o que, em nenhum caso, é exigido no Brasil) e aprovação em exame de qualificação.

A configuração desse fato numa vantagem competitiva das firmas de serviços profissionais canadenses e norte-americanas frente às brasileiras vai depender essencialmente da possibilidade de os benefícios gerados pela maior qualidade dos serviços suplantarem os custos, representados pelos maiores preços dos serviços. Provavelmente, as firmas canadenses e norte-americanas terão mais vantagens frente a mercados/clientes de maior poder aquisitivo. 


\section{Quadro 1: Regulação de serviços profissionais no Brasil, Estados Unidos e Canadá}

\begin{tabular}{|c|c|c|c|}
\hline & Brasil & EUA & Canadá \\
\hline $\begin{array}{l}\text { 1.a. Serviços de } \\
\text { engenharia: }\end{array}$ & & & \\
\hline Atividades reservadas & Sim & Sim & Sim \\
\hline Qualificação exigida & $\begin{array}{l}\text { Quatro anos de } \\
\text { estudo }\end{array}$ & $\begin{array}{c}\text { Quatro anos de esfudo } \\
\text { e de experiência } \\
\text { profissional }\end{array}$ & $\begin{array}{l}\text { Quatro anos de estudo e } \\
\text { de experiência profissional } \\
\text { e exame de qualificaçāo }\end{array}$ \\
\hline $\begin{array}{c}\text { Associação profissional } \\
\text { obrigatória }\end{array}$ & Sim & Não & $\operatorname{sim}$ \\
\hline $\begin{array}{c}\text { Formas de } \\
\text { estabelecimento, tarifas } \\
\text { e propaganda }\end{array}$ & Salário mínimo & $\begin{array}{l}\text { Restrições a tipos de } \\
\text { incorporação }\end{array}$ & Nenhuma restrição. \\
\hline $\begin{array}{l}\text { Profissionais } \\
\text { estrangeiros }\end{array}$ & $\begin{array}{l}\text { Registro temporário } \\
\text { no CREA; residência } \\
\text { prévia; contratação } \\
\text { mediante presença } \\
\text { de profissional } \\
\text { brasileiro } \\
\end{array}$ & Licença & Residência prévia e licença \\
\hline Firmas estrangeiras & $\begin{array}{l}\text { Nenhuma, mas a } \\
\text { elas se aplicam as } \\
\text { mesmas restrições } \\
\text { impostas à } \\
\text { contratação de } \\
\text { estrangeiros }\end{array}$ & $\begin{array}{c}\text { Restriçōes a investimentos } \\
\text { e número mínimo de } \\
\text { norte-americanos a } \\
\text { serem empregados }\end{array}$ & $\begin{array}{c}\text { Restriçōes a investimentos } \\
\text { e número mínimo de } \\
\text { canadenses a serem } \\
\text { empregados }\end{array}$ \\
\hline 1.b. Servicos legais: & & & \\
\hline Atividades reservadas & Sim & $\operatorname{Sim}$ & Sim \\
\hline Qualificação exigida & $\begin{array}{c}\text { Quatro anos de } \\
\text { esfudo e exame de } \\
\text { qualificação }\end{array}$ & $\begin{array}{l}\text { Sete anos de estudo e } \\
\text { exame de qualificação }\end{array}$ & $\begin{array}{c}\text { 4-7 anos de estudo, } 0,5-1 \\
\text { ano de experiência } \\
\text { profissional e exame de } \\
\text { qualificaçāo }\end{array}$ \\
\hline $\begin{array}{c}\text { Associação profissional } \\
\text { obrigatória } \\
\end{array}$ & Sim & Não & $\operatorname{Sim}$ \\
\hline $\begin{array}{c}\text { Formas de } \\
\text { estabelecimento, tarifas } \\
\text { e propaganda }\end{array}$ & $\begin{array}{c}\begin{array}{c}\text { Restriçöes à forma } \\
\text { de estabelecimento } \\
\text { e propaganda }\end{array} \\
\end{array}$ & $\begin{array}{l}\text { Restriçōes a tipos de } \\
\text { incorporaçōes }\end{array}$ & $\begin{array}{l}\text { Incorporações são } \\
\text { proibidas }\end{array}$ \\
\hline $\begin{array}{l}\text { Profissionais } \\
\text { estrangeiros }\end{array}$ & $\begin{array}{c}\text { Só atuam em direito } \\
\text { internacional; } \\
\text { residência prévia e } \\
\text { autorização OAB. }\end{array}$ & $\begin{array}{l}\text { Residência prévia e } \\
\text { exame de requalificação }\end{array}$ & $\begin{array}{c}\text { Residência prévia e exame } \\
\text { de requalificação }\end{array}$ \\
\hline Firmas estrangeiras & Idem anterior. & $\begin{array}{c}\text { Certa restrição relativa à } \\
\text { exigência de presença } \\
\text { local }\end{array}$ & $\begin{array}{c}\text { Restriçōes a investimentos, } \\
\text { associaçōes, parcerias e } \\
\text { joint-ventures, contratação } \\
\text { local mínima e exigência } \\
\text { de presença local } \\
\end{array}$ \\
\hline
\end{tabular}




\section{Quadro I: Regulação de serviços profissionais no Brasil, Estados Unidos e Canadá (continuação)}

\begin{tabular}{|c|c|c|c|}
\hline 1.c. Serviços contóbeis: & $\ldots \ldots$ & $\cdots$ & $\ldots \ldots$ \\
\hline Atividades reservadas & Sim & Sim & Poucas \\
\hline Qualificação exigida & $\begin{array}{l}\text { Quatro anos de } \\
\text { estudo }\end{array}$ & $\begin{array}{c}\text { Quatros anos de estudo, } \\
\text { 2-3 anos de experiência } \\
\text { profissional e exame de } \\
\text { qualificação }\end{array}$ & $\begin{array}{l}\text { Quatro anos de } \\
\text { estudos, } 2-2,5 \text { anos de } \\
\text { experiência profissional } \\
\text { e aprovação em exame } \\
\text { de qualificaçāo }\end{array}$ \\
\hline $\begin{array}{c}\text { Associação profissional } \\
\text { obrigatória }\end{array}$ & Sim & Não & Sim \\
\hline $\begin{array}{c}\text { Formas de } \\
\text { estabelecimento, tarifas e } \\
\text { propaganda }\end{array}$ & Sem restriçāo. & $\begin{array}{l}\text { Restriçōes a tipos de } \\
\text { incorporaçōes }\end{array}$ & $\begin{array}{c}\text { Restriçōes a tipos de } \\
\text { incorporaçōes e } \\
\text { práticas } \\
\text { multidisciplinares } \\
\end{array}$ \\
\hline Profissionais estrangeiros & Residência prévia & $\begin{array}{l}\text { Residência prévia e } \\
\text { licença }\end{array}$ & $\begin{array}{c}\text { Residência prévia e } \\
\text { licença }\end{array}$ \\
\hline Firmas estrangeiras & Nenhuma & $\begin{array}{c}\text { Restriçōes a } \\
\text { investimentos, número } \\
\text { de empregodos locais e } \\
\text { presença local }\end{array}$ & $\begin{array}{c}\text { Restriçōes a } \\
\text { investimentos, número } \\
\text { de empregados locais } \\
\text { e presença local }\end{array}$ \\
\hline
\end{tabular}

As firmas canadenses de serviços de engenharia apresentam clara vantagem em relação às de outros países, no que tange ao aprendizado dentro de contextos regulatórios mais potencializadores de capacidades através da concorrência plena. Afinal, a regulação desse setor no país não impõe quaisquer restrições à realização de propaganda, formas de estabelecimentos, tarifas cobradas e práticas etc., restrições que costumam ser nocivas às firmas de serviços profissionais.

Do mesmo modo, as firmas de serviços contábeis brasileiras se beneficiam da ausência dessas restrições, presentes em certo grau nos Estados Unidos e no Canadá. Por fim, as firmas de serviços legais brasileiras são prejudicadas pelas restriçōes à realização de propaganda, ausentes em outros países.

\section{Considerações Finais}

O exame dos arcabouços regulatórios nacionais no Brasil, EUA e Canadá referentes aos serviços abordados neste trabalho - segmentos passíveis de caracterização atual como "nãocomercializáveis" e de baixa penetração de investimentos externos diretos - nos permitiu concluir o seguinte: 
O peso das regulamentações diferenciadas, enquanto fontes de vantagens competitivas nacionalmente distintas para empresas brasileiras, canadenses e norte-americanas num contexto pós-ALCA, varia significativamente nos serviços, a julgar pela amostra aqui abordada;

- O maior grau de concorrência nesses segmentos se dá mesmo com as barreiras colocadas em termos de requisitos para a entrada nos mercados de serviços dos EUA e do Canadá, sob a forma de exigência de reconhecimento local de qualificações e demais aspectos, com ou sem restrições explícitas à operação de agentes estrangeiros;

- Tais restrições nem sempre se manifestam sob formas diretas no âmbito federal, emergindo apenas nas instâncias infrafederais e/ ou em nível das associações profissionais, patronais e sindicais. Trata-se de aspecto relevante a ser considerado pelos negociadores brasileiros;

- Vantagens/desvantagens decorrentes das atuais diferenças regulatórias e transportadas ao contexto de homogeneidade não serão necessariamente mais fortes que aquelas de origem financeira ou tecnológica; mas

- Finalmente, tudo indica que, para a competitividade das firmas brasileiras, poderá ser crucial o tempo disponível para sua adaptação ao eventual novo contexto regulatório associado à ALCA. A ausência de tempo ou o retardamento na re-adequação poderá ser bastante prejudicial.

\section{Referências bibliográficas}

Bonelli, R. (2000). Fusões e Aquisiçōes no Mercosul. IPEA, Texto para Discussão n 718.

Bortolotti, B. (2000). "Quale regolazione per le libere professioni?" Politica Economica, 16 (2). September.

Canuto, O., Alexandre, M. E Lima, G. T. (2003) "Investimentos externos diretos em serviços no Brasil e efeitos potenciais da negociação da Alca", Economia Aplicada, no prelo.

CEPAL (Comissão Econômica para a América Latina e o Caribe) (2001). La inversión extranjera en América Latina y el Caribe - Informe 2000.

CEPAL (Comissão Econômica para a América Latina e o Caribe) (2003). La inversión extranjera en América Latina y el Caribe -Informe 2002. 
Feldman, R. $\mathcal{B}$ Begun, J.W. (1985): "The welfare cost of quality changes due to professional regulation". Journal of Industrial Economics. Vol. 34, $\mathrm{n}^{\mathrm{a}} \mathrm{l}$.

Gonçalves, R. et-alii(1998). A nova economia internacional: uma perspectiva brasileira. Campus: Rio de Janeiro.

Kleiner, M.M. (2000). "Occupational licensing”. Journal of Economic Perspectives. Vol. 14, n4.

OECD (2000). Competition in professional services. DAFFE/CLP (2000) 2.

Office of Fair Trading (OFT) (2001). Competition in professions. A report by the Director General of Fair Trading. March.

Sociedade Brasileira de Estudos de Empresas Transnacionais e da Globalização Econômica (SOBEET) (2000). Carta da SOBEET: Investimentos diretos dos Estados Unidos no Brasil. Edição bimestral. Ano III, n 15.

Schroeter, J.R., Smith, S.L. E Cox, S.R. (1987). "Advertising and competition in routine legal service markets: an empirical investigation". Journal of Industrial Economics. Vol. 36, n²1.

Stephen, F.H. (2001). An Economic Perspective on the Regulation of Legal Service Markets. Evidence submitted to the Justice 1 Committee's Inquiry into the Regulation of the Legal Profession.

UNCTAD (2000). Informe sobre las inversiones en el mundo.

UNCTAD (2001). World Investment Report.

b) Sites utilizados

Associação Brasileira dos Consultores de Engenharia (ABCE). http:/l www.ibpinet.com.br/abce.

Banco Central do Brasil. http://www.bacen.gov.br.

Bureau of Economic Analysis. http://www.bea.doc.gov.

Câmara Americana de Comércio. http://www.amcham.com.br.

Câmara de Comércio Brasil-Canadá. http://www.ccbc.org.br.

Câmara de Comércio e Indústria Brasil-Alemanha. http://www.ahkbrasil.com.br.

Department of Foreign Affairs and International Trade - Government of Canada. http://www.dfait-maeci.gc.ca.

iBig 5.com. http://www.ibig5.com.

World Trade Organization (WTO). http://www.wto.org. 